International Journal of Electrical Engineering and Technology (IJEET)

Volume 11, Issue 4, June 2020, pp. 225-233, Article ID: IJEET_11_04_025

Available online at https://iaeme.com/Home/issue/IJEET?Volume=11\&Issue $=4$

ISSN Print: 0976-6545 and ISSN Online: 0976-6553

DOI: https://doi.org/10.34218/IJEET.11.4.2020.025

(C) IAEME Publication

Scopus Indexed

\title{
STRATEGY AND OPTIMIZATION OF A MIXTURE OF NONCONVENTIONAL ENERGY SOURCES IN THE ENERGY SYSTEM
}

\author{
M. Rambabu \\ GMR Institute of Technology, Rajam, Andhra Pradesh, India \\ B. Venkateswara Rao \\ VR Siddhartha Engineering College, Andhra Pradesh, India \\ G.V. Nageshkumar \\ JNTUA - Jawaharlal Nehru Technological University Anantapuramu, \\ Andhra Pradesh, India

\section{B. Sravan Kumar}

GITAM - Gandhi Institute of Technology and Management University, Visakhapatnam, Andhra Pradesh, India

\begin{abstract}
This paper treaties with design and optimization of a hybrid renewable energy sources in power system with HOMER software. The hybrid sources with renewable sources like solar, wind and battery, diesel generator are used. With these sources it going to meet the electric demand. The main objective of this paper is to design an individual renewable energy system to see the anticipated electric load with high renewable fraction \& little energy cost. To minimize the net present cost of the constraints in mixture energy system, the best optimization analysis are used like search space optimization in order to find out the best prime possible configuration. A search space is formed for each component (solar, generator, battery \& converter) using lower and upper limits of each component \& dispatch strategy. The two control strategies are nominated for this study; those are load following (LF) \& cycle charging $(C C)$. The simulation results proves that the advised model finished with lowest energy cost, less losses \& major fraction of renewable energy.
\end{abstract}

Key words: HOMER, Off-grid, Solar System, Wind Energy.

Cite this Article: M. Rambabu, B. Venkateswara Rao, G.V. Nageshkumar and B. Sravan Kumar, Strategy and Optimization of a Mixture of Nonconventional Energy Sources in the Energy System. International Journal of Electrical Engineering and Technology, 11(4), 2020, pp. 225-233.

https://iaeme.com/Home/issue/IJEET?Volume=11\&Issue $=4$ 


\section{INTRODUCTION}

These days' nonconventional energy sources are playing a vital part in the energy system. To meet the increased electrical demand nonconventional energy sources are used. The nonconventional sources like solar, tidal, biogas, wind, geothermal, biomass etc. used popularly. Out of which solar \& wind energy sources are used in this paper because of abundant availability of these sources in the nature. Majority of nonconventional energy comes either straightly or circuitously from the sun. The energy produced from solar or wind can be used for heating, cooking, lighting homes without connected to grid. It can be used for industrial \& commercial purpose also.

The off grid is a system which is used to help the people without the support of the electrical grid. To provide the smaller community in electricity the off grid is a standalone system. By using the renewable sources in the energy system like solar and wind the off grid system is designed. The energy which is generating from these renewable sources are can be directly used for the commercial or industrial purpose. The modeling and optimization for off grid system is prepared with HOMER software. To design these renewable sources in off grid hybrid system the Vijayawada city is considered. In this paper solar/wind/diesel generator/battery/converter are used by using the HOMER software. The different combinations of sources are used by two control strategy. From these sources it is going to meet the electrical demand for the certain specified area.

The following author Chaouki Ghenai et.al [1] they deal with off-grid hybrid renewable sources in power system. They reduce the cost and carbon emission of the system at the load constant by using only solar energy. The author R.Nazir et.al [2] is deal with the renewable energy to reduce the system cost by using the solar and micro hydro which is integrated with utility grid. And the some of the authors like L. K. Gan, and M A Mueller [3] these are deals with the renewable energy sources in the power system. They design different combination of the sources to meet the demand. But in the most of the designs they used more solar generation when compare to the other sources. M.Rambabu et.al [4] demonstrated the balancing of energy of a microgrid using the support vector machine model to meet the load demand and various conditions. Naik [5] illustrated the energy management by using particle swarm optimization technique in order to meet the load demand by connecting without and with storage devices and utilities. The revision explained in this paper and extended by using the HOMER software by earlier work [6-8].

The objective of this paper is to design off-grid hybrid renewable sources like PV and wind to meet the desired load in Vijayawada with the help of HOMER software [9]. By these sources it is going to minimize the cost, excess energy with low environmental impact.

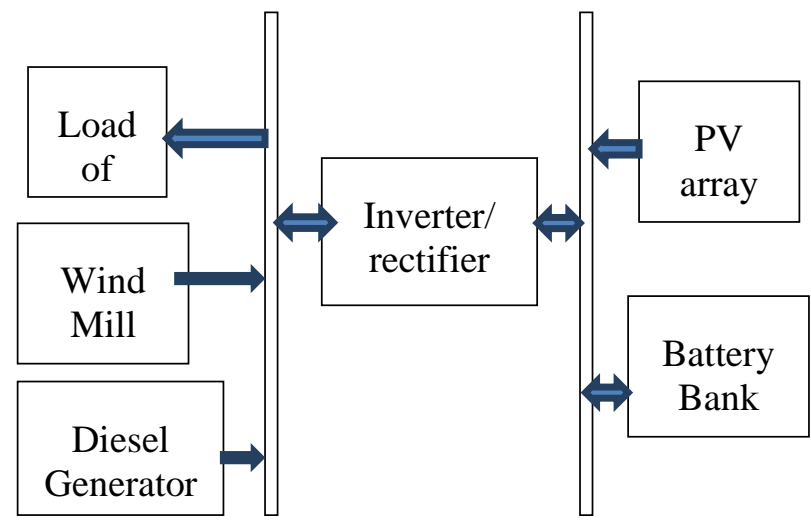

Figure 1 Segment diagram of off-grid system 


\section{HYBRID POWER SYSTEM MODELING}

Mixer power system shown in Figure 1, Involves of PV, wind, diesel generator, and inverter and battery panel is provender to the AC bus [10].

\subsection{PV Array}

Power output from the PV array is stated in equation 1.

$$
P_{P V}=f_{P V} Y_{P V} \frac{I_{T}}{I_{S}}
$$

$f_{P V}$ : Derating factor of PV

YPV : rated capacity of PV $(\mathrm{kW})$

IT : solar radiation $(\mathrm{kW} / \mathrm{m} 2)$

IS : $1 \mathrm{~kW} / \mathrm{m} 2$ (at standard test conditions)

$$
P_{P V, S T C}=\left(N_{S} \times N_{P}\right) P_{m, S T C}
$$

$P_{m, S T C}:$ PV unit Energy output

$N_{S}:$ Number of modules associated in series

$N_{P}:$ Number of structures in parallel.

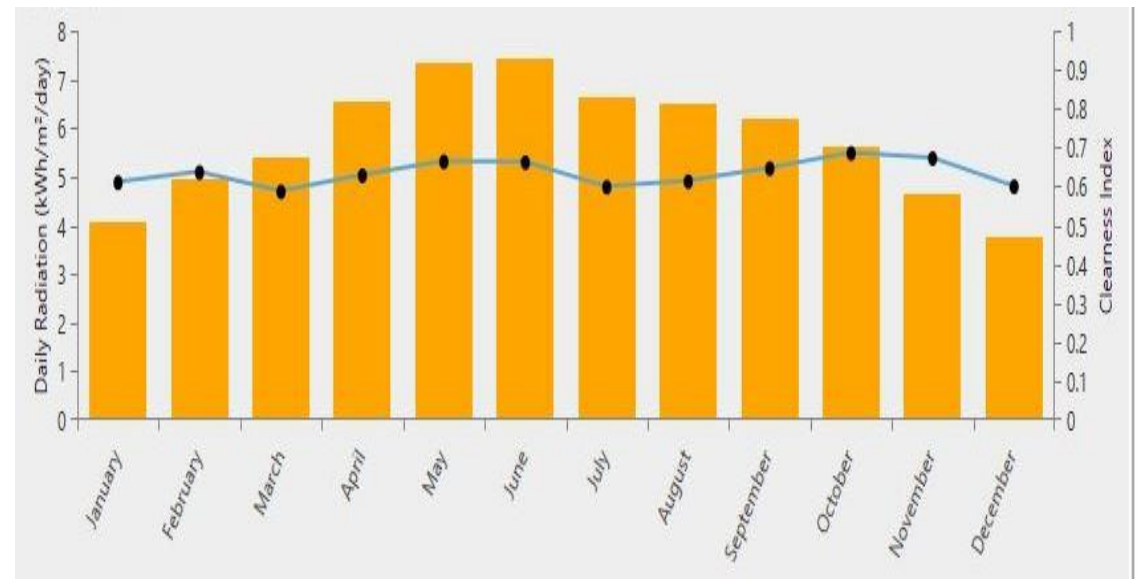

Figure 2 Monthly Average Solar Global Horizontal Irradiance data.

\subsection{Inverter/Rectifier}

Inverter/Rectifier is attached between DC bus \& AC bus as showed in Figure 1.It has guiding process restricted on the energy flow, which transfer energy between PV array \& the AC load when act as inverter, act as a rectifier in the occasion of charging the battery from diesel generator.

\subsection{Wind}

NASA website used for taking the monthly average wind data based on the longitude \& latitude of the specified location \& it is showed in Figure. 3. 


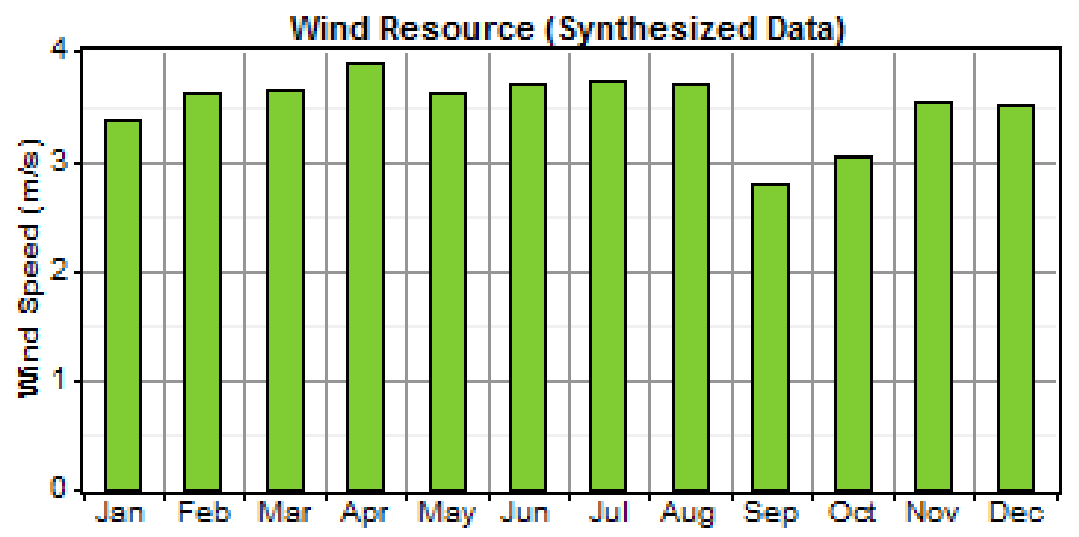

Figure 3 Monthly Average wind data.

\subsection{Battery}

Battery source inclusion into system help to store the excess power generation, which may be utilized in deficit generation conditions.

$$
\operatorname{SOC}(t)=\operatorname{SOC}(0)+\eta_{C} \sum_{k=0}^{t} P_{C}(K)+\eta_{d} \sum_{k=0}^{t} p_{d}(k)
$$

SOC(0)- battery initial SOC.

$P_{C}$ - charged energy; $p_{d}$ - discharge energy;

$\eta_{C}$ - charging efficiency; $\eta_{d}$ - discharging efficiency

\subsection{Diesel Generator}

If the energy supplied by the PV, wind\& battery bank is not in positions to meet the load then diesel generator act as a backup energy generator [11].

\subsection{Load}

AC load is measured by energy serving of fifteen houses in Vijayawada.

\subsection{Optimization \& control approaches}

For outcome best probable optimization investigation in mixture energy system to lessen the net present cost for chosen constraints. Load following and cycle charging type control approaches used in this paper. Nonconventional energy sources are used to charge the battery but power produced by generators does not charge battery in Load following approach. In cycle charging approach, battery charges with excess energy produced by diesel generators when the generator drives more than it necessary [12-13].

HOMER attains the model for a no.of possible design establishments. After analytical every design, it selects the one that happens the load with the system limitations at the less life cycle cost. HOMER performs its optimization \& creates the best matched mixture renewable system for off grid use based on the COE, operating cost \& losses. 


\section{DESIGN AND SIMULATION RESULTS}

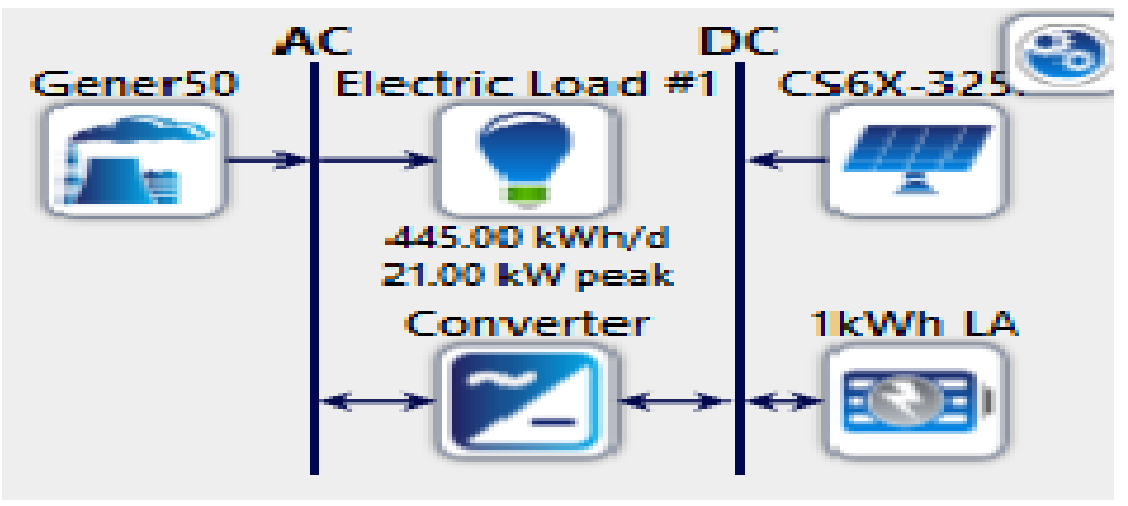

Figure 4 Solar, battery, diesel generator integrated off-grid system.

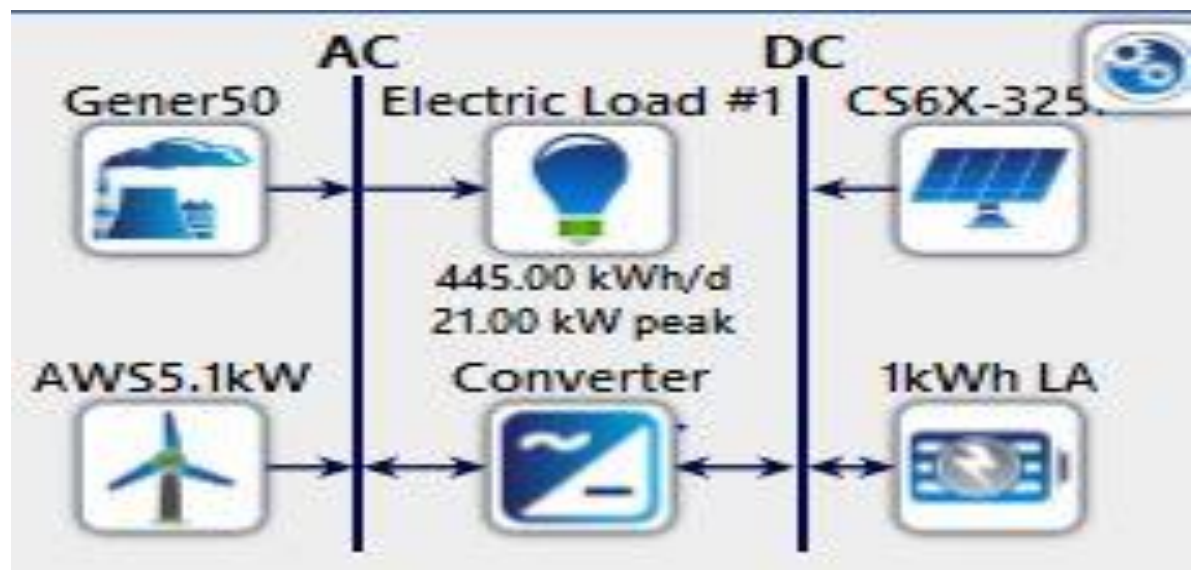

Figure 5 Wind, solar, battery and diesel generator combined off-grid.

Modeling \& optimization of an off-grid mixture renewable energy sources like PV \& wind are design by using the HOMER software. To encounter the demand of the energy the PV and battery are linked to the DC bus the wind, generator and load are associated to the AC bus and the converter are coupled between the DC and AC. The battery is used for the charging and discharging by depending on the load. In this software there are two control strategies one is load following (LF) and the other one is cycle charging (CC). In the LF renewable energy sources charge the battery but generator do not but in the $\mathrm{CC}$ case if generators produce more energy than this surplus electricity charge the battery. By using these sources the five different combinations of sources are taken like (i) wind, solar, battery, diesel generator, converter it is shown in Figure. 5. (ii) wind, diesel generator, battery and converter (iii) solar, diesel generator, battery and converter is presented in Figure. 4. (iv) diesel generator, battery and converter (v) only generator. From these different combinations of sources there will be a change in cost, losses and excess electricity. The below Table 1, shows the total generation from the three sources in the off-grid system. From the total generation the solar generate $108197 \mathrm{kWh} / \mathrm{yr}(46.57 \%)$, wind generates $82307 \mathrm{kWh} / \mathrm{yr}(35.43 \%)$ and from the generator it generates $41800 \mathrm{kWh} / \mathrm{yr}(18 \%)$. By these sources the combination solar and wind generates more energy compare to the generator and the total cost of the system also reduced. Table 2 gives complete information of consumption and losses. AC load with $69.92 \%$. There is an excess of electricity with $20.514 \%$ which is generate more from the solar than wind. The losses are present in the battery and converter is $9.5 \%$. Table 3 shows the different combination of sources with constant AC load of $162425 \mathrm{kWh} / \mathrm{yr}$. 
Strategy and Optimization of a Mixture of Nonconventional Energy Sources in the Energy System

Table 1 Energy Generation from different sources

\begin{tabular}{|l|c|c|}
\hline \multicolumn{1}{|c|}{ Source/ Generation } & In kWh/yr & In kWh/yr. \% \\
\hline PV Array & 108197 & 46.57 \\
\hline Wind Source & 82307 & 35.43 \\
\hline Diesel Generator & 41800 & 18 \\
\hline Overall generation & 232304 & 100 \\
\hline
\end{tabular}

Table 2 Losses and utilization due to different devices

\begin{tabular}{|l|c|c|}
\hline \multicolumn{1}{|c|}{ MEASURE } & In kWh/yr & In kWh/yr. \% \\
\hline Consumption of AC load & 162425 & 69.92 \\
\hline Consumption of DC load & 0 & 0 \\
\hline Excess of Electricity & 47655 & 20.514 \\
\hline Battery Losses & 12490 & 5.376 \\
\hline Converter Losses & 9734 & 4.19 \\
\hline Total Generation & 232304 & 100 \\
\hline
\end{tabular}

Table 3 Different combination of sources with constant AC load

\begin{tabular}{|l|c|c|c|c|}
\hline \multicolumn{1}{|c|}{ Combinations } & $\begin{array}{c}\text { Total } \\
\text { Generation in } \\
\mathbf{k W h} / \mathbf{y r} .\end{array}$ & $\begin{array}{c}\text { Surplus } \\
\text { Electricity } \\
\text { in } \mathbf{k W h} / \mathbf{y r}\end{array}$ & $\begin{array}{c}\text { losses in } \\
\text { Converter } \\
\mathbf{k W h} / \mathbf{y r}\end{array}$ & $\begin{array}{c}\text { Battery losses in } \\
\mathbf{k W h} / \mathbf{y r}\end{array}$ \\
\hline W,S,G,B,C & 232304 & 47655 & 9734 & 12490 \\
\hline W,G,B,C & 193718 & 105 & 13408 & 17780 \\
\hline S,G,B,C & 217329 & 27902 & 12317 & 14685 \\
\hline G,B,C & 199212 & 0 & 15807 & 20980 \\
\hline G & 162425 & 0 & - & - \\
\hline
\end{tabular}

Table 4 COE \& NPC prices for diverse mixture of sources

\begin{tabular}{|l|c|c|c|c|}
\hline \multicolumn{1}{|c|}{ Arrangements } & $\begin{array}{c}\text { COE (cost of } \\
\text { energy) in Rs/ } \\
\text { kWh }\end{array}$ & $\begin{array}{c}\text { NPC (Net Present } \\
\text { Cost) in Rs }\end{array}$ & $\begin{array}{c}\text { Operational } \\
\text { Cost in Rs/yr }\end{array}$ & $\begin{array}{c}\text { Preliminary } \\
\text { Cost in Rs }\end{array}$ \\
\hline W,S,G,B,C & 3.58 & $7.53 * 10 \mathrm{e} 6$ & $0.5132 * 10 \mathrm{e} 6$ & 891200 \\
\hline W,G,B,C & 5.67 & $11.91 * 10 \mathrm{e} 6$ & $0.8632 * 10 \mathrm{e} 6$ & 754600 \\
\hline S,G,B,C & 3.91 & $8.21 * 10 \mathrm{e} 6$ & $0.6129 * 10 \mathrm{e} 6$ & 286800 \\
\hline G,B,C & 6.48 & $13.6 * 10 \mathrm{e} 6$ & $1.04 * 10 \mathrm{e} 6$ & 146000 \\
\hline G & 11.26 & $23.6 * 10 \mathrm{e} 6$ & $1.83 * 10 \mathrm{e} 6$ & 30000 \\
\hline
\end{tabular}

W- wind; S- Solar; G- Generator; B- Battery; C- Converter

The above Table 3 and Table 4 shows the different combinations of the sources in the each combination there is a change in generation, excess electricity, cost, COE, NPC, converter and battery losses, but the AC load is constant for every combination and DC load is not considered. By comparing these combinations change in generation can be observed. The generation is more in the case of solar comparing to wind and generator. When the solar is combined with the other sources then excess electricity is more while compare to the wind and generator. In wind generation there is less excess electricity due to fewer losses. In the combination of generator, battery, converter $(\mathrm{G}, \mathrm{B}, \mathrm{C})$ losses of converter and battery are more, these losses can be reduced by adding any one of the renewable energy generating systems to $(\mathrm{G}, \mathrm{B}, \mathrm{C})$ combination, that can be easily observed from the above tables. In solar and wind combination (W, S, G, B, C) the losses are less. The operating cost is less for the solar, wind, generator, battery and converter combination (W, S, G, B, C), thus it is the best combination to implement.

The below figures, Figure. 6, Figure.7, and Figure.8 shows the one day evaluation of generation and load for different conditions. Whenever the solar and wind is generating 
energy then the generator is in rest condition but the load is constant for every combination of the generation there is change in the excess generation.

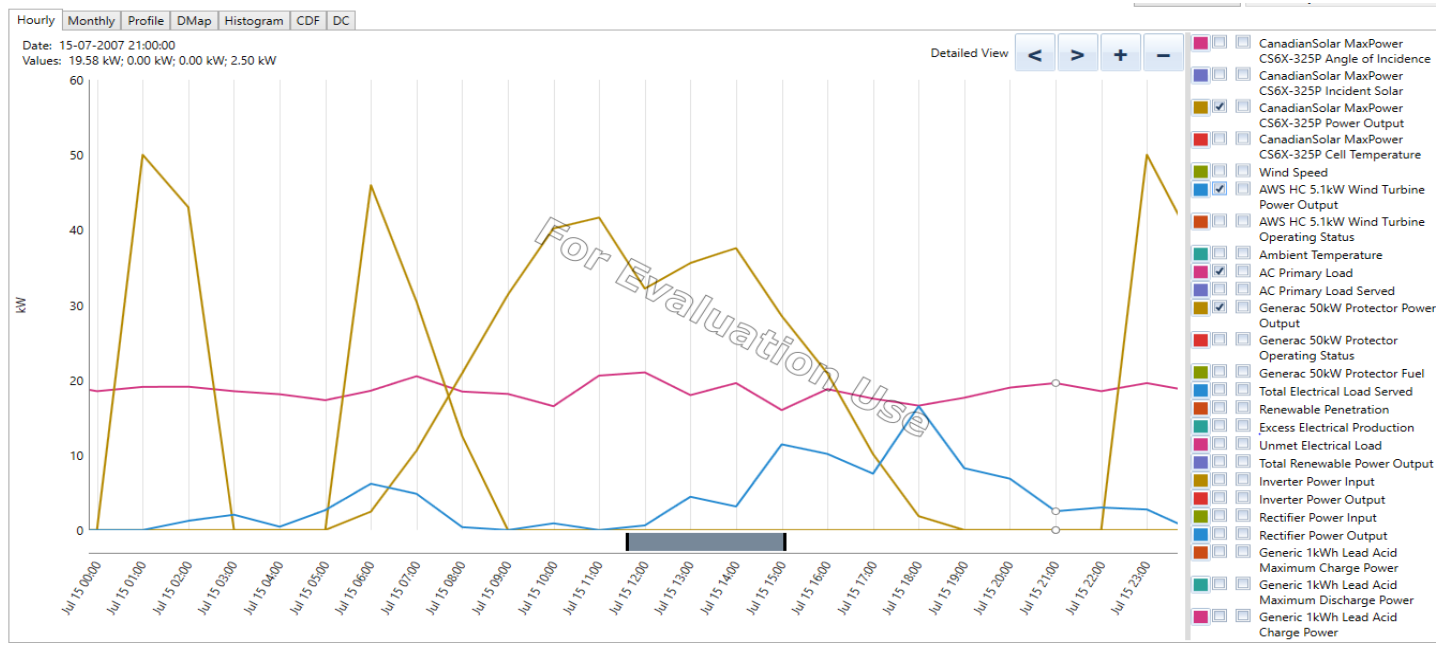

Figure 6 Represents the one day generation to meet the load from solar, wind and generator

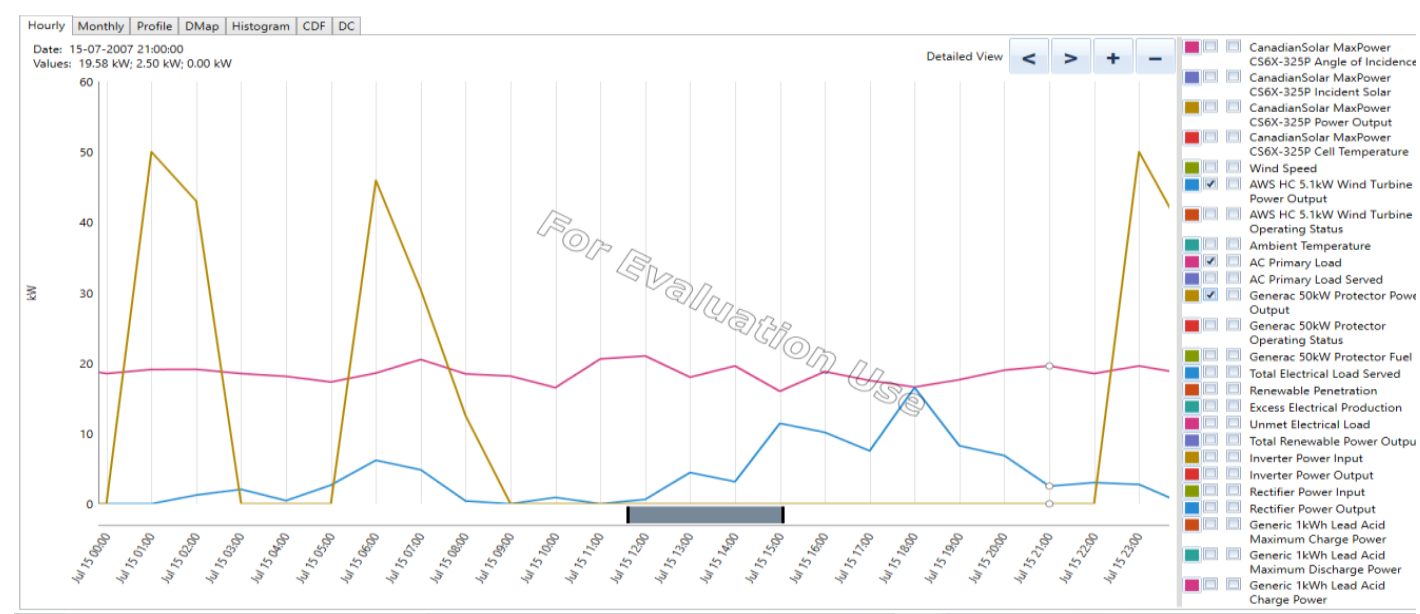

Figure 7 Represents the one day generation to meet the load from wind and generator

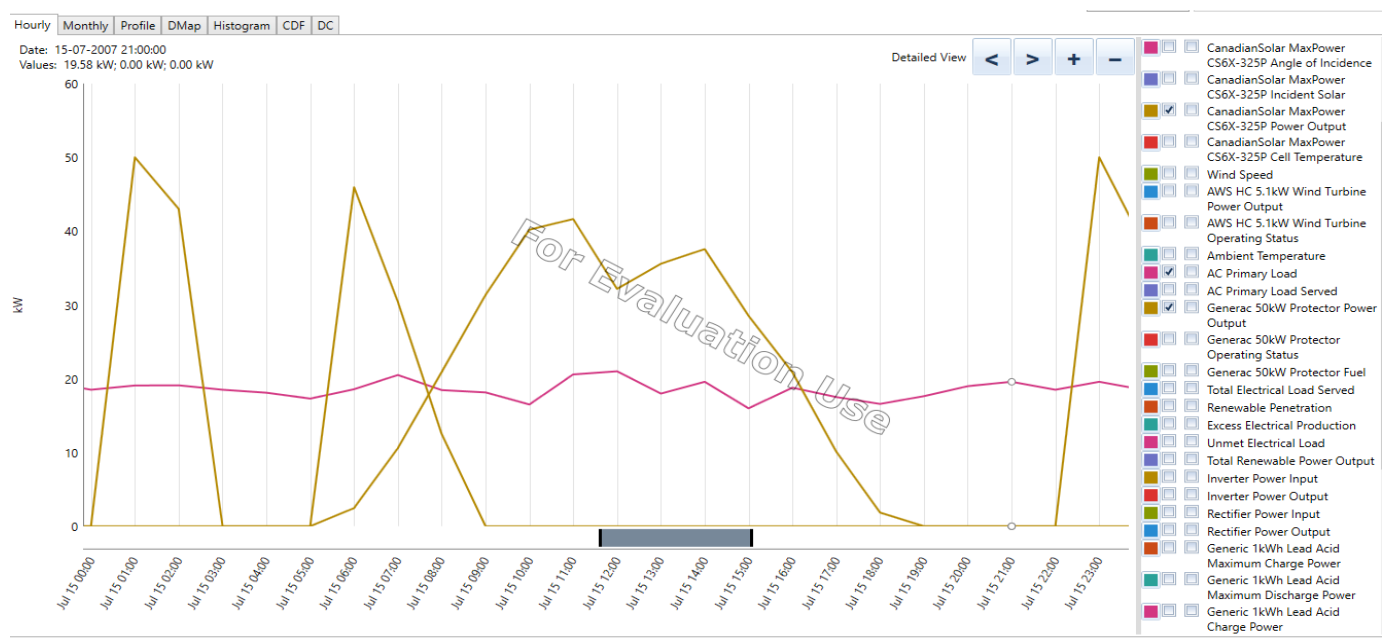

Figure 8 Represents the one day generation to meet the load from solar and generator 


\section{CONCLUSION}

Optimizations stood implemented in this instance to find a combination of off grid energy system to meet the power-driven load. The grid combination energy system comprises 3 energy generators (solar system, wind \& Diesel generator) shared with batteries \& inverter. Optimization analysis was charity to test the enactment $\&$ the cost of the advised combination off-grid system. The outcome validates that solar/Wind/DG/Battery/ Inverter energy system meets the annual electrical load of the specific area with low losses $\&$ minimum operating cost.

\section{REFERENCES}

[1] Ghenai, Chaouki, Tareq, Adel, and A K Hamid. (2017) "Modeling and optimization of hybrid solar-diesel-battery energy system." 7th IEEE International Conference on Modeling, Simulation, Applied Optimization (ICMSAO), 2017, pp. 1-5.

[2] Nazir, Refdinal, H D Laksono, E P Waldi, E Ekaputra, and P Coveria. (2014) "Renewable energy sources optimization: a micro-grid model design", Energy Procedia, Vol. 52, pp. 316-327.

[3] L. K. Gan, and M A Mueller, (2015.) "Hybrid wind-photovoltaic-diesel-battery system sizing tool development using empirical approach, life-cycle cost and performance analysis: A case study in Scotland," Energy Conversion and Management, Vol. 106, pp.479-494.

[4] M. Rambabu, G. V. Nagesh Kumar, and S. Siva Nagaraju, (2016) "Energy management of micro grid using support vector machine (SVM) model," IIOAB J., vol. 7, no. 11.

[5] B. B. Naik and M. Rambabu, (2019) "Energy Management by Using Renewable Energy Sources," International Journal of Innovative Technology and Exploring Engineering volume no. 8, pp. 315-322.

[6] Laly, M. J., Elizabeth P. Cheriyan, and Abraham T. Mathew. (2016) "Particle swarm optimization based optimal power flow management of power grid with renewable energy sources and storage." In 2016 Biennial International Conference on Power and Energy Systems: Towards Sustainable Energy (PESTSE), pp. 1-6. IEEE.

[7] Ridwan, Mohamad, Andri Pradipta, Sjamsjul Anam, and Mochamad Ashari. (2018) "Particle swarm optimization based maximum power point tracking for seawater battery application." In 2018 IEEE International Conference on Innovative Research and Development (ICIRD), pp. 1-6. IEEE.

[8] Tayab, Usman Bashir, Fuwen Yang, Mohamed El-Hendawi, and Junwei Lu. (2018) "Energy Management System for a Grid-Connected Microgrid with Photovoltaic and Battery Energy Storage System." In 2018 Australian \& New Zealand Control Conference (ANZCC), pp. 141-144. IEEE.

[9] R. Sen and S C B Charyya, (2014)"Off-grid electricity generation with renewable energy technologies in India: An application of HOMER", Renewable Energy, Vol. 62, pp. 388398.

[10] Nehrir, C Wang, K Strunz, and alameh Z., (2011) "A Review of Hybrid Renewable/ Alternative Energy Systems for Electric Energy Generation: Configuration, Control, and Applications", IEEE Transactions on Sustainable Energy, Vol. 2, No. 4, pp. 392-403, October.

[11] J K M Chandani, C Agarwal, M Sahi, (2012) "Economic Feasibility of Hybrid Biomass/PV/ Wind System for Remote Village Using HOMER", International Journal of Advanced Research in Electrical, Electronics and Instrumentation Engineering, Vol. 1, No 2, pp. 49-53, August 
[12] U Bindu and Parekh, (2011) "Modelling and Simulation of Distributed Generation System Using HOMER Software", International Conference on Recent Advancements in Electrical, Electronics and Control Engineering, pp-328-332.

[13] A Heydari, and A Askarzadeh, (2016) "Optimization of a biomass based photovoltaic energy plant for an off-grid application subject to loss of energy supply probability concept”, Applied Energy, Vol. 165, pp. 601-611.

[14] Sh. Shokolakova, S.A. Keshuov, A.A. Saukhimov, K.K. Tokhtibakiev, O. Ceylan and E. Shuvalova, (2018) Optimization of Mode in Distribution Electrical Grid by Using Renewable Energy Sources for Rural Energy Supply, International Journal of Mechanical Engineering and Technology, 9(7), pp. 1396-1404 